\title{
La alternativa cooperativa en la prestación de servicios públicos sostenibles
}

(The cooperative alternative in the provision of sustainable public services)

\author{
Vega María Arnáez Arce ${ }^{1}$ \\ Universidad de Deusto (España)
}

Sumario: I. A modo de introducción. II. La colaboración del cooperativismo en la prestación de servicios públicos. 2.1. Aproximación al estado de la cuestión. 2.2. Especial referencia al papel de las cooperativas de iniciativa social. III. Identidad cooperativa para la mejora de los servicios públicos. IV. Conclusiones. V. Bibliografía.

Summary: I. Introduction. II. The collaboration of cooperativism in the provision of public services. 2.1. Approach to the state of the question. 2.2. Special reference to the role of social initiative cooperatives. III. Cooperative identity for the improvement of public services. IV. Conclusions V. Bibliography.

Resumen: De acuerdo con la Declaración de Identidad Cooperativa aprobada en el año 1995 por la Asamblea General de la Alianza Cooperativa Internacional, la cooperativa puede definirse como una asociación autónoma de personas unidas voluntariamente para hacer frente a necesidades y aspiraciones comunes a través de una empresa de propiedad conjunta y democráticamente controlada, regida por un sistema singular de principios y valores.

En el presente trabajo, se analiza la instrumentalización jurídica de la colaboración del cooperativismo en la prestación de servicios públicos como estrategia para su mejoramiento, en la que cobra especial importancia el séptimo principio cooperativo, que aboga por que estas entidades trabajen en pro del desarrollo sostenible de sus comunidades con arreglo a las políticas adoptadas por sus socios.

Palabras clave: Colaboración público-privada; Colaboración público-cooperativa; servicios públicos; servicios asistenciales.

Abstract: According to the Declaration of Cooperative Identity approved in 1995 by the General Assembly of the International Cooperative Alliance, the

1 Profesora Contratada Doctora de Derecho Administrativo. Email: vegamaria. arnaez@deusto.es. 
cooperative can be defined as an autonomous association of persons united voluntarily to meet common needs and aspirations through a company owned jointly and democratically controlled, governed by a unique system of principles and values.

In this paper, we analyze the legal instrumentation of cooperative collaboration in the provision of public services as a strategy for its improvement, in which the seventh cooperative principle, which advocates that these entities work for the sustainable development of their communities in accordance with the policies adopted by their partners.

Keywords: Public-private collaboration; Public-cooperative collaboration; public services; services. 


\section{A modo de introducción}

De acuerdo con la Declaración de Identidad Cooperativa aprobada en el año 1995 por la Asamblea General de la Alianza Cooperativa Internacional2 ${ }^{2}$ la cooperativa puede definirse como una asociación autónoma de personas unidas voluntariamente para hacer frente a necesidades y aspiraciones comunes a través de una empresa de propiedad conjunta y democráticamente controlada, regida por un sistema singular de principios y valores (Morillas 2008, 37).

Precisamente, lo que distingue a las sociedades cooperativas del resto de formas de empresa que operan en el mercado, no es tanto la clase de actividad que desempeñan, como la naturaleza intrínseca que refleja los principios y valores rectores de su organización y funcionamiento. $Y$ es que encuentran sus bases en la autoayuda, la responsabilidad, la democracia, la igualdad, la equidad y la solidaridad. Valores que, conforme a la precitada Declaración, se ponen en práctica por medio de los siguientes principios: adhesión voluntaria y abierta; gestión democrática; participación económica; autonomía e independencia; educación, capacitación e información; cooperación entre cooperativas; e interés por la comunidad.

En el supuesto que nos ocupa, a saber, la colaboración del cooperativismo en la prestación de servicios públicos como estrategia para su mejoramiento, cobra especial importancia el séptimo principio cooperativo, que aboga por que estas entidades trabajen en pro del desarrollo sostenible de sus comunidades con arreglo a las políticas adoptadas por sus socios. Según Gadea Soler, Sacristán Bergia y Vargas Vasserot, esto significa que, en las cooperativas, las acciones socialmente responsables no vienen determinadas por motivos externos - comerciales, principalmente- , sino que están medularmente ligadas a su identidad (Gadea, Sacristán, Vargas 2009,46). Es decir, es su propio carácter servicial lo que las conduce a favorecer el progreso socioeconómico de sus miembros y de su entorno, mirando siempre al futuro de las generaciones de hoy y de mañana (Giraldo 2003, 128).

En este tenor, cabe afirmar que el movimiento cooperativo ha destacado desde sus orígenes por mantener un fuerte compromiso con la sociedad. Es más, suele presumirse que todas aquellas cooperativas que integran en su objeto social como fines prioritarios de su actuación la educación, la vivienda, la atención socio-sanitaria, la cooperación para

2 Véase: http://www.aciamericas.coop/Principios-y-Valores-Cooperativos-4456 (Última consulta, 23 de enero de 2017). 
el desarrollo o el medioambiente, entre otros, contribuyen a los intereses generales. Ahora bien, son las cooperativas sin ánimo de lucro y, dentro de éstas, las calificadas como de iniciativa social, las que, remitiéndonos a lo que se expondrá en el próximo capítulo, responden a los mismos de una manera más concreta.

Es por todo ello que las Administraciones Públicas, en el contexto actual de una economía global marcada por la crisis sistémica y el aumento de las desigualdades, precisan, cada vez más, del apoyo y la participación activa del Tercer Sector, en general, y de las sociedades cooperativas, en particular, como agentes de desarrollo e innovación arraigados en nuestra comunidad y que conviven en armonía con ella, para la satisfacción eficaz y eficiente de las necesidades básicas de la ciudadanía.

Y ello, en la medida en que su fundamentación parte del papel y de las funciones que el Movimiento Cooperativo y el Tercer Sector vienen llevando a cabo en la sociedad, toda vez que, a diferencia de lo que ocurre con las empresas capitalistas, las entidades que lo conforman persiguen objetivos y tratan de dar respuesta a demandas que no se expresan en términos meramente económicos o monetarios.

\section{La colaboración del cooperativismo en la prestación de servicios públicos}

\subsection{Aproximación al estado de la cuestión}

Hay que comenzar este apartado señalando que la simplificación administrativa se presenta como uno de los mayores retos y como el objetivo más inmediato del Derecho administrativo de nuestros días, esencial para la construcción de un nuevo modelo de Administración Pública que sirva con objetividad los intereses generales y actúe acorde con los principios reconocidos en el artículo 103 de la Constitución (Palomar 2010, 338-345).

Un nuevo paradigma estructural y funcional, así como de interacción con los ciudadanos, que se proponga lograr un desarrollo institucional, económico y social sostenible.

Al efecto, el fenómeno de la externalización se configura como una tendencia imparable de transformación de las Administraciones que, impulsado por las corrientes doctrinales de la denominada Nueva Gestión Pública, posibilita la incorporación a las mismas de destrezas y habilidades técnicas provenientes del resto de sectores, lo que se traduce en una gran oportunidad de obtener servicios públicos especializados 
e innovadores. No sólo eso. Abre la puerta, también, a que los agentes públicos conozcan los esquemas éticos y las prácticas responsables que presiden el día a día de otros actores económicos y sociales, como pueden ser las cooperativas, y se adhieran a ellos.

Por consiguiente, cabe apuntar a la gestión de ciertos servicios públicos a través de organizaciones de la economía social, y más concretamente, de sociedades cooperativas, como uno de los elementos clave en la instauración de una Administración Pública que tenga como meta la realización de los principios constitucionales de eficacia y eficiencia y, a su vez, la protección de los aspectos más sólidos del modelo productivo del sector en que se integra. Un protagonismo o, cuando menos, una creciente relevancia que, para Argudo Périz, estaría justificada por la vocación social y comunitaria y el desarrollo en el sector de servicios del cooperativismo.

En palabras del propio autor, tales argumentos determinan necesariamente «una confluencia en el campo de los servicios a las personas y a la comunidad [...]» (Argudo 2007, 182).

Confluencia que el Tribunal de Justicia de la Unión Europea, en su sentencia de 28 de enero de 2016, ha respaldado expresamente respecto al ámbito de las prestaciones de índole social y sanitaria. Lo ha hecho por considerar que el Derecho de la Unión no se opone a las normativas nacionales que permiten a las autoridades locales atribuir la prestación de ciertos servicios mediante adjudicación directa, sin forma alguna de publicidad, a entidades sin ánimo de lucro, siempre que el marco legal y convencional en el que actúan contribuya realmente a una finalidad social y a la prosecución de objetivos de solidaridad y eficiencia presupuestaria ${ }^{3}$.

Sin entrar ahora en el debate en torno a las especificidades del concepto del lucro en la esfera cooperativa, merece indicar que la Disposición Adicional Primera de la Ley 27/1999, de 16 de julio, de Cooperativas ${ }^{4}$, establece que "podrán ser calificadas como sociedades cooperativas sin ánimo de lucro las que gestionen servicios de interés colectivo o de titularidad pública [...]». Y es que hace alusión a la realidad que venimos apuntando a lo largo del trabajo. Claro que es pre-

3 Para más detalle, véase: Gimeno Feliú, José María. «Un paso firme en la construcción de una contratación pública socialmente responsable mediante colaboración con entidades sin ánimo de lucro en prestaciones sociales y sanitarias». Observatorio de Contratación Pública, opiniones, n. ${ }^{\circ} 232$, de 9 de febrero de 2016: http://www.obcp. es/index.php/mod.opiniones/mem.detalle/id.232/relcategoria.208/relme nu.3/chk.faf01cea691c17e6c632c328db10de0f (Última consulta, 25 de enero de 2018).

4 España. Ley 27/1999, de 16 de julio, de Cooperativas. Boletín Oficial del Estado, n. ${ }^{\circ} 170$, de 17 de julio de 1999. 
ciso percatarse, conforme a la normativa estatal vigente y a las reflexiones de Argudo Périz, de que las cooperativas sin ánimo de lucro, cuyo exponente más destacado son las cooperativas calificadas como de iniciativa social que analizaremos a continuación, no constituyen una nueva clase de cooperativa, sino «una especialidad de cualquier tipo de cooperativa dentro de las clasificaciones que se contemplan legislativamente» (Argudo 2007, 183).

\subsection{Especial referencia al papel de las cooperativas de iniciativa social}

Las cooperativas de iniciativa social son, según el artículo 106.1 de la mencionada Ley de Cooperativas, aquéllas que, sin ánimo de lucro y con independencia de su clase, tienen por objeto social, bien la prestación de servicios asistenciales realizando actividades de naturaleza social, o bien el desarrollo de cualquier actividad económica que tenga por finalidad la integración laboral de personas en situación o riesgo de exclusión social y, en general, la satisfacción de necesidades sociales no atendidas por el mercado.

Al igual que la norma estatal, la práctica totalidad de la legislación autonómica en vigor las prevé, bajo diferentes denominaciones, tales como de «bienestar social», «integración social» o «servicios sociales $»^{5}$. En nuestro caso, la Ley 4/1993, de 24 de junio, de Cooperativas de Euskadi6dedica su artículo 127 a regular los sujetos y las mo-

5 Véanse (en su versión actualizada): arts. 153 a 156 de la Ley 2/1998, de 26 de marzo, de Sociedades Cooperativas de Extremadura; arts. 125 y 126 de la Ley 5/1998, de 18 de diciembre, de cooperativas de Galicia; art. 107 de la Ley 4/1999, de 30 de marzo, de Cooperativas de la Comunidad de Madrid; art. 112 de la Ley 4/2001, de 2 de julio, de Cooperativas de La Rioja; art. 124 de la Ley 4/2002, de 11 de abril, de Cooperativas de la Comunidad de Castilla y León; arts. 138 y 139 de la Ley 1/2003, de 20 de marzo, de cooperativas de las Illes Balears; arts. 130 y 131 de la Ley 8/2006, de 16 de noviembre, de Sociedades Cooperativas de la Región de Murcia; art. 78 de la Ley Foral 14/2006, de 11 de diciembre, de Cooperativas de Navarra; arts. 183 y 184 de la Ley del Principado de Asturias 4/2010, de 29 de junio, de Cooperativas; arts. 148 y 149 de la Ley 11/2010, de 4 de noviembre, de Cooperativas de Castilla-La Mancha; art. 94 de la Ley 14/2011, de 23 de diciembre, de Sociedades Cooperativas Andaluzas; arts. 125 a 127 de la Ley de Cantabria 6/2013, de 6 de noviembre, de Cooperativas de Cantabria; art. 77 del Decreto Legislativo 2/2014, de 29 de agosto, del Gobierno de Aragón, por el que se aprueba el texto refundido de la Ley de Cooperativas de Aragón; art. 98 del Decreto Legislativo 2/2015, de 15 de mayo, del Consell, por el que se aprueba el texto refundido de la Ley de Cooperativas de la Comunitat Valenciana; y art. 143 de la Ley 12/2015, de 9 de julio, de Cooperativas de Cataluña.

6 Euskadi. Ley 4/1993, de 24 de julio, de Cooperativas de Euskadi. Boletín Oficial del País Vasco, n. ${ }^{\circ} 135$, de 19 de julio de 1993. 
dalidades de las cooperativas de integración social7, mientras que en su artículo 137.2 establece que "las entidades cooperativas que contribuyan a la promoción del interés general de Euskadi mediante el desarrollo de sus funciones serán reconocidas de utilidad pública por el Gobierno Vasco [...]».Ley pionera en abordar esta posible calificación, sujeta a que la cooperativa — que, normalmente y por lógica, será de iniciativa social - en cuestión fomente la materialización de fines de interés general por medio de sus actividades, participando en la prestación de servicios públicos, por ejemplo.

En desarrollo de dichas previsiones, se aprobaron los Decretos 64/1999, de 2 de febrero, que recoge el Reglamento de sociedades cooperativas de utilidad pública del País Vasco ${ }^{8}$, y 61/2000, de 4 de abril, sobre cooperativas de iniciativa social ${ }^{9}$.

El primero, además de fijar los requisitos (artículos 5 y 6) y el procedimiento (artículos 7 a 12) para la declaración de utilidad pública de las cooperativas, determina que de su obtención derivan los siguientes derechos: utilizar la mención en todos sus documentos; ser oídas, a través de las Federaciones o Confederaciones correspondientes, en la elaboración de disposiciones generales relacionadas directamente con las materias de su actividad y en la elaboración de programas de transcendencia para las mismas; y gozar de las exenciones, bonificaciones, subvenciones y demás beneficios de carácter económico, fiscal y administrativo que en cada caso se acuerden. Luego no cabe duda de la conveniencia de alcanzar tal condición, en cuanto se refiere a las oportunidades de crecimiento y desarrollo de estas entidades, al acceso a las ayudas y a la protección de los poderes públicos, y al reconocimiento del servicio que prestan, no sólo a sus asociados, sino también al conjunto de la sociedad en general.

El Decreto 61/2000, por su parte, empieza advirtiendo que su contenido no interfiere con la norma que tipifica ciertas cooperativas como de «integración social» según el precitado artículo 127 de la Ley de Cooperativas de Euskadi. Así pues, en su artículo 1 circunscribe la calificación de iniciativa social a aquellas cooperativas que, sin ánimo de lucro e independientemente de su clase, tienen un determinado objeto

7 Que deben estar constituidas mayoritariamente por disminuidos físicos o psíquicos, si bien es cierto que pueden participar como socios entidades públicas responsables de la prestación de cualesquiera servicios sociales.

8 Euskadi. Decreto 64/1999, de 2 de febrero, por el que se aprueba el Reglamento sobre procedimientos y requisitos relativos a las sociedades cooperativas de utilidad pública. Boletín Oficial del País Vasco, n. ${ }^{\circ} 33$, de 17 de febrero de 1999.

9 Euskadi. Decreto 61/2000, de 4 de abril, por el que se regulan las Cooperativas de Iniciativa Social. Boletín Oficial del País Vasco, n. ${ }^{\circ} 82$, de 3 de mayo de 2000. 
social que el propio precepto especifica y que coincide con lo expuesto respecto a su equivalente estatal. Supedita la carencia de ánimo de lucro a que las cooperativas incluyan de manera expresa en sus Estatutos: a) que los resultados positivos que se produzcan en un ejercicio económico no podrán ser distribuidos entre sus socios; b) que las aportaciones de los socios al capital social, tanto obligatorias, como voluntarias, no podrán devengar un interés superior al legal del dinero, sin perjuicio de su posible actualización; c) el carácter gratuito del desempeño de los cargos del Consejo Rector, sin perjuicio de las compensaciones económicas procedentes por los gastos en los que pudieran incurrir en su actuación; y d) que las retribuciones de los socios trabajadores o, en su caso, de los socios de trabajo y de los trabajadores por cuenta ajena, no podrán superar el $150 \%$ de las retribuciones que, en función de la actividad y categoría profesional, establezca el Convenio colectivo aplicable al personal asalariado del sector. $Y$ a todo eso hay que añadir, acorde con su artículo 3 y con lo concluido en el apartado anterior, que estas cooperativas se rigen por las normas propias del concreto tipo de cooperativa en que se encuadran.

Si bien el Anteproyecto de Ley de Cooperativas de Euskadi presentado por el Gobierno Vasco el 24 de mayo del pasado año se remite mayormente a lo que acaba de exponerse -entre los cambios, sobresale el agregado de un nuevo artículo sobre cooperativas de inserción-, lo cierto es que el nuevo texto pretende aumentar la seguridad jurídica de las relaciones internas y externas de las cooperativas, adaptando la actividad de control y fomento cooperativo que ejerce la Administración Pública y que se explicará en el próximo capítulo al actual entorno jurídico, económico e institucional ${ }^{10}$.

En este sentido y para terminar, debe ponerse de manifiesto que el movimiento cooperativo constituye uno de nuestros principales motores de generación de riqueza y creación de empleo, dado su peso en el conjunto de la economía vasca. Por proporcionar algunos datos, en el año 2015 el 2,5\% de la actividad empresarial se realizó con la forma jurídica de sociedad cooperativa, concentrando el 6,9\% del empleo; la Seguridad Social registró 1.555 empresas cooperativas en alta, con un total de 55.343 trabajadores, lo que arroja un tamaño medio de 35,6 trabajadores por cooperativa, la ratio más elevada del Estado, cuyo promedio es de 14,8; y el Registro de Cooperativas de la Dirección de Economía Social del Gobierno Vasco cifró el número de cooperativas

10 Para más detalle, véase: http://www.euskadi.eus/gobierno-vasco/contenidos/ noticia/2016_05_24_328 75/es_32875.html (Última consulta, 27 de enero de 2018). 
en 1.096 , a las que se unen otras 844 entidades que son cooperativas pequeñas - figura con régimen y normativa particulares, en virtud de la Ley $6 / 2008$, de 25 de junio ${ }^{11}$ — de modo que el total de cooperativas alcanzaba las 2.750 al finalizar el año ${ }^{12}$.

Todo ello, no olvidemos, en su apuesta por el desarrollo sostenible y la cohesión social y territorial de la Comunidad, trasladando a la práctica los principios y valores cooperativos. Y en ese desafío, las cooperativas de iniciativa social y/o de utilidad pública vienen desempeñando un papel elemental, por tratar de satisfacer necesidades colectivas de toda índole en aquellos espacios que la Administración no ha podido cubrir o no ha cubierto como corresponde. Contribuyendo, en definitiva, a la realización de finalidades públicas y de servicio a la sociedad.

\section{Identidad cooperativa para la mejora de los servicios públicos}

La principal ventaja que representan las organizaciones del Tercer Sector y, en lo que aquí interesa, las sociedades cooperativas, para el sistema es, de acuerdo con Álvarez Rodríguez, «la generación de economías de proximidad», como resultado de su especial enlace al territorio y a sus gentes (Álvarez 2012, 410). Vínculo que, entendemos, deriva a su vez de la idiosincrasia participativa de estas entidades.

Haciendo nuestras las palabras de Divar Garteiz-Aurrecoa, «en las cooperativas, la participación de sus miembros es su fuerza endógena» (Divar 2010, 265). Es decir, bien su régimen particular de propiedad y de distribución de ganancias, bien el carácter democrático que debe ostentar su gestión, las separan de las estructuras de poder capitalistas y justifican su intenso arraigo social, su tendencia a la creación de empleo estable y de calidad, su flexibilidad para adaptarse a cambios y afrontar crisis y, a fin de cuentas, su potencialidad para conformar una alternativa sólida que impulse un verdadero desarrollo local sostenible.

Es por ello que nos parece esencial ofrecer una breve reflexión en torno al significado y el alcance de la colaboración del mundo cooperativo en la prestación de servicios públicos, como expresión de la evolución del rol de los ciudadanos en sus relaciones con los poderes públicos; una ciudadanía cada vez más exigente a la hora de conocer, influir

11 Para más detalle, véase: Ley 6/2008, de 25 de junio, de la Sociedad Cooperativa Pequeña de Euskadi. Boletín Oficial del País Vasco, n. ${ }^{\circ}$ 127, de 4 de julio de 2008.

12 Consejo Económico y Social Vasco. «Comunidad Autónoma del País Vasco. Memoria socioeconómica 2015» (pp.32-33): http://www.cesegab.com/Portals/0/Libros/ MSE2015.pdf (Última consulta, 27 de enero de 2017). 
y formar parte de cuantas decisiones afectan al funcionamiento de unos servicios públicos a cuyo mantenimiento contribuyen con el pago de sus impuestos.

En esta línea, debe señalarse que el Derecho administrativo actual trata de introducir un nuevo modelo de gestión pública que se nutra de unas instituciones y represente unas prácticas más abiertas y accesibles, con una creciente implicación de los administrados en ellas. O lo que es lo mismo, que fomente una ciudadanía informada, dinámica y corresponsable para con la actividad de la Administración, en la que la prestación coparticipada de servicios públicos goce de mayor protagonismo.

Ello no obstante, cabe advertir que es el Derecho cooperativo el que, desde sus inicios, ha apuntado a la necesidad de que las Administraciones Públicas respalden esta otra forma de hacer empresa, más solidaria y cercana, que supone el fenómeno cooperativo y colaboren con él para el correcto desempeño de sus funciones y la consecución de su fin último, el bienestar común.

Así pues, el artículo 108 de la Ley 27/1999 de Cooperativas anuncia como tarea de interés general el fomento del cooperativismo. Cometido que encuentra su punto de partida y de llegada en la propia Constitución, por concederle ésta en su artículo 129.2 un reconocimiento expreso que asegura su desarrollo formal y funcional e integrarlo, al mismo tiempo, como vía para el cumplimiento de los objetivos de contenido social que procura. Y ello, con el propósito de potenciar, no sólo la figura más clásica de la economía social, sino, sobre todo, la más representativa de sociedad participativa (Gallastegi 2016, 3-9).

La Ley de Cooperativas de Euskadi va más allá y pide a los poderes públicos estimular la creación de cooperativas con la finalidad de desarrollar y mejorar los servicios públicos (artículo 137.1). A lo que el Anteproyecto de Ley que viene a substituirla añade el deber de impulsar su participación en la gestión de éstos (artículo 145.4). A título de ejemplo, alude a la constitución de cooperativas de servicios públicos, cuyo marco de actuación deberá ser controlado, en todo caso, por las entidades públicas que las promuevan. Eso sí, entre las medidas concretas para la verdadera efectividad de dicho fomento destacan aquéllas tendentes a vivificar su presencia, cuantitativa y cualitativa, en la actividad prestacional de la Administración Pública vasca, que deberá encargarse, entre otros, de favorecer su participación en los procedimientos de contratación.

En este contexto, merece destacar que el Consejo Superior de Cooperativas de Euskadi, máximo órgano de promoción y difusión del cooperativismo desde la década de los 80 en nuestra Comunidad, cen- 
tra sus esfuerzos y su actuación en asesorar a la Administración autonómica en materia cooperativa y en defender los intereses concertados en torno al proyecto cooperativo vasco, toda vez que asume, también, la representación de las cooperativas, componiendo el cauce para su integración y participación en la gestión pública ${ }^{13}$.

Habida cuenta de todo lo anterior y para acabar, podemos afirmar que la colaboración con cooperativas se manifiesta, no sólo como la opción preferente para dar respuesta a las necesidades sociales no suficientemente cubiertas por el Estado, sino también como la forma idea para que los ciudadanos participen más y mejor en los asuntos públicos. Para que, toda vez que se respeten los valores y principios cooperativos, los usuarios de los servicios públicos sean tomados en cuenta para su diseño, planificación y prestación, en aras de su accesibilidad e integridad $y$, por ende, su calidad.

Y es que no se equivocan Juliá Igual y Meliá Martí al sostener que «[...] las cooperativas, hoy más que nunca, están llamadas a ser un elemento clave y dinamizador de un verdadero desarrollo social, económico y sostenible, ya que por sus especiales características permiten que éste sea más cohesionado social y territorialmente, algo a lo que una sociedad más justa y equitativa no puede renunciar» (Juliá y Meliá 2004, 56).

\section{A modo de conclusión}

En el contexto actual, en el que se pone en cuestión el funcionamiento y la validez del denominado Estado del Bienestar, las Administraciones Públicas necesitan, cada vez más, la cooperación y participación activa del tercer sector como agente de innovación que trabaja para la satisfacción eficaz y eficiente de las necesidades sociales asistenciales, que no se expresan en términos económicos o monetarios.

El proceso de reestructuración, reforma e innovación de las Administraciones Públicas en clave de potenciar su competitividad, eficacia y eficiencia, apuesta por la interacción con los ciudadanos, quienes demandan un papel cada vez más activo en la planificación, la ejecución y la evaluación de las políticas públicas que tienen por objeto la prestación de servicios asistenciales a la población.

13 La definición de su naturaleza jurídica, organización, competencias y funcionamiento están regulados en la Ley de Cooperativas de Euskadi, desarrollada a estos efectos por el Decreto 213/1999, de 11 de mayo, así como por el Reglamento interno del Consejo, aprobado por Acuerdo adoptado en sesión plenaria de 26 de julio de 1999. 
En este sentido, el movimiento cooperativo, basado en los valores de solidaridad, democracia, equidad, igualdad, autoayuda y auto-responsabilidad, ha destacado desde su origen por su contribución a la promoción del desarrollo y realización de fines de interés general, de tal forma y manera que se presume que sirven al interés general todas aquellas sociedades cooperativas que integren en su objeto social fines prioritarios tales como la asistencia socio-sanitaria, la educación, la vivienda, la protección y defensa del medio ambiente, el fomento de la economía social y la protección de la paz social y ciudadana, entre otros.

A tal efecto, merece significarse cómo la vigente Ley 4/1993, de 24 de junio, de Cooperativas del País Vasco fue la primera en regular el reconocimiento o la posible clasificación de las sociedades cooperativas como "de utilidad pública», cuando promuevan mediante su actividad el desarrollo y la realización de fines de interés general. En su desarrollo se aprobaron los Decretos 64/1999, de 2 de febrero y 61/2000, de 4 de abril, por los que se establece el régimen jurídico de las cooperativas de utilidad pública e iniciativa social respectivamente.

\section{Bibliografía}

ÁlVAREZ RODRÍGUEZ, Juan Fernando. 2012. «El futuro de la economía social». En: Fajardo García, Gemma, y Senent Vidal, María José. Economía social: identidad, desafíos y estrategias. RULESCOOP, Valencia: 405-412.

ARGUDO PÉRIZ, José Luis. 2007. «Las cooperativas sin ánimo de lucro: ¿vuelta a los orígenes o respuesta a las nuevas necesidades sociales?». Revista Vasca de Economía Social, núm. 3: 179-201.

ARNÁEZ ARCE, Vega María. 2014. «La participación ciudadana en la prestación de servicios públicos. El supuesto de las cooperativas de utilidad pública en la Comunidad Autónoma del País Vasco». REVESCO. Revista de Estudios Cooperativos, núm. 116: 7-32.

ATXABAL RADA, Alberto y Arnáez Arce, Vega María. 2013. «Las cooperativas de utilidad pública e iniciativa social. Aspectos administrativos y fiscales». Boletín de la Asociación Internacional de Derecho Cooperativo, núm. 47: 199-228.

BURZACO SAMPER, María. 2016. «Contrataciones públicas socialmente responsables: la necesidad de reconsiderar el potencial de la contratación pública en la consecución de objetivos sociales». CIRIEC-España, Revista de Economía Pública, Social y Cooperativa, núm. 86: 281-310.

CONSEJO ECONÓMICO Y SOCIAL VASCO. "COMUNIDAD AUTÓNOMA DEL PAÍS VASCO. MEMORIA SOCIOECONÓMICA 2015»: HTTP:/MWW.CESEGAB.COM/PORTALS/O/LIBROS/MSE2015. PDF (ÚLTIMA CONSULTA, 27 de enero de 2017). 
DIVAR GARTEIZ-AURRECOA, Javier. 2010. «Las cooperativas ante la crisis económica». Boletín de la Asociación Internacional de Derecho Cooperativo, núm. 44: 263-283.

GADEA SOLER, Enrique, Sacristán Bergia, Fernando, y Vargas Vasserot, Carlos. 2009. Régimen jurídico de la sociedad cooperativa del siglo XXI. Realidad actual y propuestas de reforma. Dykinson S.L., Madrid.

GALLASTEGI ORMAETXEA, Itxaso. 2016. «El modelo subvencional para el fomento del cooperativismo, a debate». Comunicación presentada en el XVI Congreso de Investigadores en Economía Social y Cooperativa «Economía Social: crecimiento económico y bienestar» organizado por CIRIEC-España y celebrado en Valencia los días 19-21 de octubre de 2016.

GARCÍA ARÉJULA, Jesús María y Bakaikoa Azurmendi, Baleren. 2016. "Contratos públicos adjudicados a sociedades cooperativas en el País Vasco entre 2010 y 2012». REVESCO, Revista de Estudios Cooperativos, núm. 120: 76-98.

GIMENO FELIÚ, José María. 2016. «Un paso firme en la construcción de una contratación pública socialmente responsable mediante colaboración con entidades sin ánimo de lucro en prestaciones sociales y sanitarias». Observatorio de Contratación Pública, opiniones, núm. 232, de 9 de febrero de 2016: http://www.obcp.es/index.php/mod. opiniones/mem.detalle/id.232/ relcategoria.208/relmenu.3/chk.faf01cea691c17e6c632c328db10de0f (Última consulta, 25 de enero de 2017).

GIRALDO NEIRA, Octavio. 2003. Identidad, valores y principios cooperativos. Análisis y significados de la Declaración de la Alianza Cooperativa Internacional. Cali.

JULIÁ IGUAL, Juan Francisco y Meliá Martí, Elena. 2014. «El futuro del cooperativismo en una Europa en construcción». En: VVAA. El futuro de las cooperativas en una Europa en crecimiento. CIRIEC-España, Valencia: 13-60.

MERINO, Santiago. 2016. "Posibilidades del cooperativismo en un nuevo modelo de servicios públicos sociosanitarios y su concreción en el País Vasco», CIRIEC-España, Revista de Economía Pública, Social y Cooperativa, núm. 87:139-176.

MORILLAS JARILLO, María José. 2008. Las sociedades cooperativas. lustel, Madrid.

PALOMAR OLMEDA, Alberto. 2010. "Simplificación administrativa». En: La ordenación de las actividades de servicios: comentarios a la Ley 17/2009, de 23 de noviembre. Quadra-Salcedo Fernández del Castillo, Tomás (Dir.). Aranzadi, Cizur Menor: 338-345. 


\section{Derechos de autor}

El Boletín de la Asociación Internacional de Derecho Cooperativo es una revista de acceso abierto lo que significa que es de libre acceso en su integridad inmediatamente después de la publicación de cada número. Se permite su lectura, la búsqueda, descarga, distribución y reutilización legal en cualquier tipo de soporte sólo para fines no comerciales y según lo previsto por la ley; sin la previa autorización de la Editorial (Universidad de Deusto) o el autor, siempre que la obra original sea debidamente citada (número, año, páginas y DOI si procede) y cualquier cambio en el original esté claramente indicado.

\section{Copyright}

The International Association of Cooperative Law Journal is an Open Access journal which means that it is free for full and immediate access, reading, search, download, distribution, and lawful reuse in any medium only for non-commercial purposes, without prior permission from the Publisher or the author; provided the original work is properly cited and any changes to the original are clearly indicated. 